Anais da Academia Brasileira de Ciências (2016) 88(2): 923-932

(Annals of the Brazilian Academy of Sciences)

Printed version ISSN 0001-3765 / Online version ISSN 1678-2690

http://dx.doi.org/10.1590/0001-3765201620150107

www.scielo.br/aabc

\title{
Mesothelin as a biomarker for ovarian carcinoma: a meta-analysis
}

\author{
KRISTIAN MADEIRA ${ }^{1,2}$, EDUARDO R. DONDOSSOLA ${ }^{1}$, BRUNA F. DE FARIAS ${ }^{1}$, CARLA S. \\ SIMON ${ }^{1}$, MARIA C.M. ALEXANDRE ${ }^{1}$, BRUNO R. SILVA ${ }^{3}$ and MARIA INÊS ROSA ${ }^{1,2}$ \\ ${ }^{1}$ Laboratório de Epidemiologia, Bloco da Saúde, Universidade do Extremo Sul Catarinense, \\ Av. Universitária, 1105, sala 26, Universitário, 88806-000 Criciúma, SC, Brasil \\ ${ }^{2}$ Programa de Pós-Graduação em Saúde Coletiva, Bloco da Saúde, Universidade do Extremo Sul \\ Catarinense, Av. Universitária, 1105, sala 13, Universitário, 88806-000 Criciúma, SC, Brasil \\ ${ }^{3}$ Programa de Residência em Ginecologia e Obstetrícia, Hospital e Maternidade Marieta Konder \\ Bornhausen, Av. Cel. Marcos Konder, 1111, Centro, 88301-303 Itajaí, SC, Brasil \\ Manuscript received on April 9, 2015; accepted for publication on July 10, 2015
}

\begin{abstract}
The objective of this work was to estimate the accuracy of mesothelin as a biomarker for ovarian cancer. A quantitative systematic review was performed. A comprehensive search of the Medline, LILACS, SCOPUS, Embase, Cochrane Central Register of Controlled Trials, Biomed Central, and ISI Web of Science databases was conducted from January 1990 to June 2015. For inclusion in this systematic review, the papers must have measured mesothelin levels in at least two histological diagnoses; ovarian cancer (borderline or ovarian tumor) vs. benign or normal ovarian tissue. For each study, 2 x 2 contingency tables were constructed. We calculated the sensitivity, specificity and diagnostic odds ratio. The verification bias was performed according to QUADAS-2. Statistical analysis was performed with the software Stata 11, Meta-DiSc ${ }^{\circledR}$ and RevMan 5.2. Twelve studies were analyzed, which included 1,561 women. The pooled sensitivity was 0.62 (CI 95\% $0.58-0.66$ ) and specificity was 0.94 (CI 95\% $0.92-0.95$ ). The DOR was 38.92 (CI $95 \% 17.82$ - 84.99). Our systematic review shows that mesothelin cannot serve alone as a biomarker for the detection of ovarian cancer.
\end{abstract}

Key words: ovarian tumors, mesothelin, meta-analysis, biomarker, statistical.

\section{INTRODUCTION}

Despite the development of new treatments and therapies, designed to improve the five-year survival rate, ovarian cancer still remains the most fatal cancer of the female reproductive tract (Jemal et al. 2009). In 2013, approximately 22,240 women in the United States were diagnosed with invasive epithelial ovarian cancer (EOC) and an estimated

Correspondence to: Maria Inês da Rosa

E-mail: mir@unesc.net
14,000 women with EOC died (Siege et al. 2013). Malignant surface epithelial tumors (carcinomas) are the most common ovarian cancer, accounting for $90 \%$ of cases, and have the highest case-fatality among gynecological malignancies (Kobel et al. 2008).

Considerable effort is underway to identify screening strategies that accurately diagnose ovarian cancer in its early stages, when it is most treatable (Abdel-Azeez et al. 2010). Biomarkers 
that can be measured in blood products are of particular interest for their potential to provide a low-cost, noninvasive screening modality suitable for use in large populations.

There is a need to improve the diagnosis and prognosis of ovarian carcinoma. Mesothelin is a novel biomarker, which are expressed in serous ovarian carcinoma and can be measured in serum and other body fluids, including urine, by using ELISA. Mesothelin is an antigen present in normal mesothelium, mesotheliomas, ovarian carcinomas, and some squamous cell carcinomas (Chang and Pastan 1996). Mesothelin (MSLN) is a $40-\mathrm{kDa}$ glycosylphosphatidyl inositol (GPI)-linked protein that is normally present on the mesothelial cells lining the peritoneum. MSLN is overexpressed in ovarian cancer tissues with a poor clinical outcome (Huang et al. 2006). Mesothelin expression is increased in ovarian cancer tissues and a soluble form is detectable in blood. Elevated serum levels of mesothelin are detectable in $40-67 \%$ of patients with ovarian cancer (Hassan et al. 2006).

The diagnosis of ovarian neoplasms is a common problem in clinical practice. Although the majority of adnexal masses are benign, the main objective of diagnostic evaluation is to exclude or confirm the diagnosis of malignancy. We performed a systematic review and meta-analysis to verify the accuracy of mesothelinasa predictor of ovarian cancer.

\section{MATERIALS AND METHODS}

All of the methods for analysis, inclusion/exclusion criteria, data extraction and quality assessment were specified in advance. We performed a systematic review according to a prospective protocol using PRISMA-statement guidelines (Liberati et al. 2009). The review protocol is registered at PROSPERO (registration number: CDR42014009574; http:// www.crd.york.ac.uk/prospero/).
We searched MEDLINE, Embase, Cochrane Central Register of Controlled Trials, IBECS, BIOSIS, Web of Science, SCOPUS, Congress Abstracts and Grey Literature (Google scholar; British Library) from January 1990 to June 2015. We used the following terms, both as text words and as appropriate; Medical Subjects Heading (MeSH) or equivalent subject heading/thesaurus terms: "ovarian tumor" OR "ovarian cancer". These aforementioned terms were combined with "mesothelin". The search had no language restrictions. The references list all available primary studies that were reviewed to identify additional relevant citations. A copy of the complete search strategy is available on request.

The abstracts/titles identified from the search, were screened by two reviewers (K.M. and M.I.R.). Disagreements about the inclusion or exclusion of studies were initially resolved by consensus, and if consensus was not possible, disagreements were arbitrarily resolved by a third reviewer (B.F.F.).

We included case-control and cohort studies, prospective or retrospective, that evaluated women with ovarian tumors (benign or malignant), measured serum mesothelin levels and performed surgery to conduct histopathological analysis.

Index test - The diagnostic test consisted of the serum mesothelin analysis (concentration $\mathrm{nmol} / \mathrm{l}$ ).

Reference standard - The diagnostic reference was the result of the histological analysis of standard paraffin-embedded sections. For inclusion in this systematic review, the papers must have measured mesothelin levels in at least two histological diagnoses; ovarian cancer (borderline or ovarian cancer) vs. benign or normal ovarian tissue. Thus, the primary outcome analyzed was the mesothelin levels (borderline or ovarian cancer vs. benign lesions or normal tissues). The reviewed studies were independently identified by two investigators (M.I.R. and K.M.). The final inclusion or exclusion of a study was made with a standard checklist. Disagreements about a study's inclusion 
or exclusion were resolved by consensus, and when this procedure was not possible, the decision relied on a third reviewer (L.R.M.).

We extracted data in duplicate (M.I.R. and K.M.) including the number and characteristics of patients and the healthcare setting. Data were abstracted as $2 \times 2$ tables regarding the mesothelin levels and the histologic diagnosis (ovarian cancer vs. benign lesions or normal tissues).

All articles meeting the eligibility criteria were assessed for methodological quality. Quality was assessed with the Diagnostic Accuracy Studies tool recommended by the Cochrane Collaboration, the Quality Assessment of Diagnostic Accuracy Studies (QUADAS-2). This tool comprises four domains: patient selection, index test, reference standard, and flow and timing. Each domain is assessed in terms of the risk of bias, and the first three domains are also assessed in terms of concerns regarding applicability. Signaling questions are included to help judge the risk of bias (Hassan et al. 2006). The quality assessment of the studies was independently performed by B.R.S. and K.M. Any disagreement was resolved by consensus.

STATISTICAL ANALYSIS

For each study, 2 x 2 contingency tables were constructed in which all cases were classified as ovarian cancer or benign lesions. We calculated the true-positive rate (TPR; sensitivity), specificity, and false-positive rate (FPR; 1 - specificity) (Liberati et al. 2009). When $2 \times 2$ tables had a cell with a value of 0 , the calculations were corrected with the addition of 0.5 in the cell, and when a study contained two cells with the value of 0 , it was excluded from the analysis (Whiting 2011). Bivariate analysis was used to calculate the pooled estimates of sensitivity, specificity, and likelihood ratios (LRs) along with 95\% confidence intervals (CIs) for the summary estimates (Altman 1999). The bivariate model preserves the 2-dimensional nature of the diagnostic data by analyzing the logit- transformed sensitivity and specificity of each study in a single model and considers both withinstudy and between-study variability, in contrast to the Littenberg and Moses method, which departs from a fixed effects model (Reitsma et al. 2005). To detect the cut-off threshold effects, the relationship between sensitivity and specificity was evaluated using the Spearman correlation coefficient. Pooled estimates were calculated only for studies showing sufficient clinical and statistical homogeneity. $I^{2}$ or $Q$ tests (commonly used in meta-analysis) are not recommended for assessing statistical homogeneity in diagnostic reviews because they do not consider the association between sensitivity and specificity (Gatsonic 2006). The prevalence was calculated according to the following equation: $(\mathrm{TP}+\mathrm{FN}) /$ (total number of patients studied) extracted from contingency tables. The diagnostic odds ratio (DOR) can relate to different combinations of sensitivity and specificity. The DOR describes the odds of positive test results in participants with disease compared with the odds of positive test results in those without disease. A single diagnostic odds ratio corresponds to a set of sensitivities and specificities depicted by the SROC. It may change according to the threshold and to the ROC curve used to define an abnormal examination, resulting in an expected trade-off between sensitivity and specificity.

A summary receiver operating characteristic curve was generated using data from all thresholds, using the Littenberg and Moses method (Reitsma 2005). Additionally, the area under the curve (AUC) summarizes the inherent capacity of a test to discriminate a diseased from a non-diseased subject. Accurate tests usually have AUCs close to 1 , and poor tests usually have AUCs close to 0.5 (Deeks et al. 2005). Sensitivity analyses were performed to assess the excluded studies with a high risk of verification bias according to QUADAS-2. To analyze publication bias, inverted funnel plots of the logarithmic odds ratio (OR) of the individual studies were plotted against sample size (Irwig et al. 
1994). Statistical analysis was performed with the software Stata 11 (StataCorp, College Station, TX, USA), Meta-DiSc ${ }^{\circledR}$ (Clinical Biostatistics Unit, Ramón y Cajal Hospital, Madrid, Spain) (version 1.4) and with RevMan 5.2 (The Nordic Cochrane Centre, Copenhagen, Denmark) (StataCorp 2013, Review Manager 2012, Zamora et al. 2006).

\section{RESULTS}

The search identified a total of 111 citations, of which 52 were potentially relevant after initial evaluation. From these studies, 40 full articles were excluded. Twelve primary studies (Hassan et al. 2006, Abdel-Azeez et al. 2010, Bandiera et al. 2013, Ho et al. 2005, Ibrahim et al. 2014, McIntosh et al. 2004, Moraes 2012, Qiao and Li 2013, Scholler et al. 1999, 2008, Shah et al. 2009, Wu et al. 2014) involving 1561 women met the criteria for inclusion and were analyzed (Figure 1).
The main characteristics of the selected studies are shown in Table I. Retrospective and prospective studies were included for a total of 1561 women; the prevalence of ovarian cancer was $42.09 \%$ (range $15.22 \%$ to $77.78 \%$ ) and included a total of 406 ovarian cancer cases.

Nine studies (Hassan et al. 2006, Abdel-Azeez et al. 2010, Bandiera et al. 2013, Ho et al. 2005, Ibrahim et al. 2014, McIntosh et al. 2004, Moraes 2012, Qiao and Li 2013, Wu et al. 2014) were prospective, and three studies (Scholler et al. 1999, 2008, Shah et al. 2009) fulfilled all QUADAS-2 criteria. In two studies (Bandiera et al. 2013, Scholler et al. 1999), there was unclear risk of bias in patient selection, and two studies (Moraes 2012, Scholler et al. 2008) showed a high risk of bias in patient selection. One study (McIntosh et al. 2004) showed high risk of bias in the index test and flow and timing. Three studies (McIntosh et al. 2004, Moraes 2012, Scholler et al. 2008) were classified
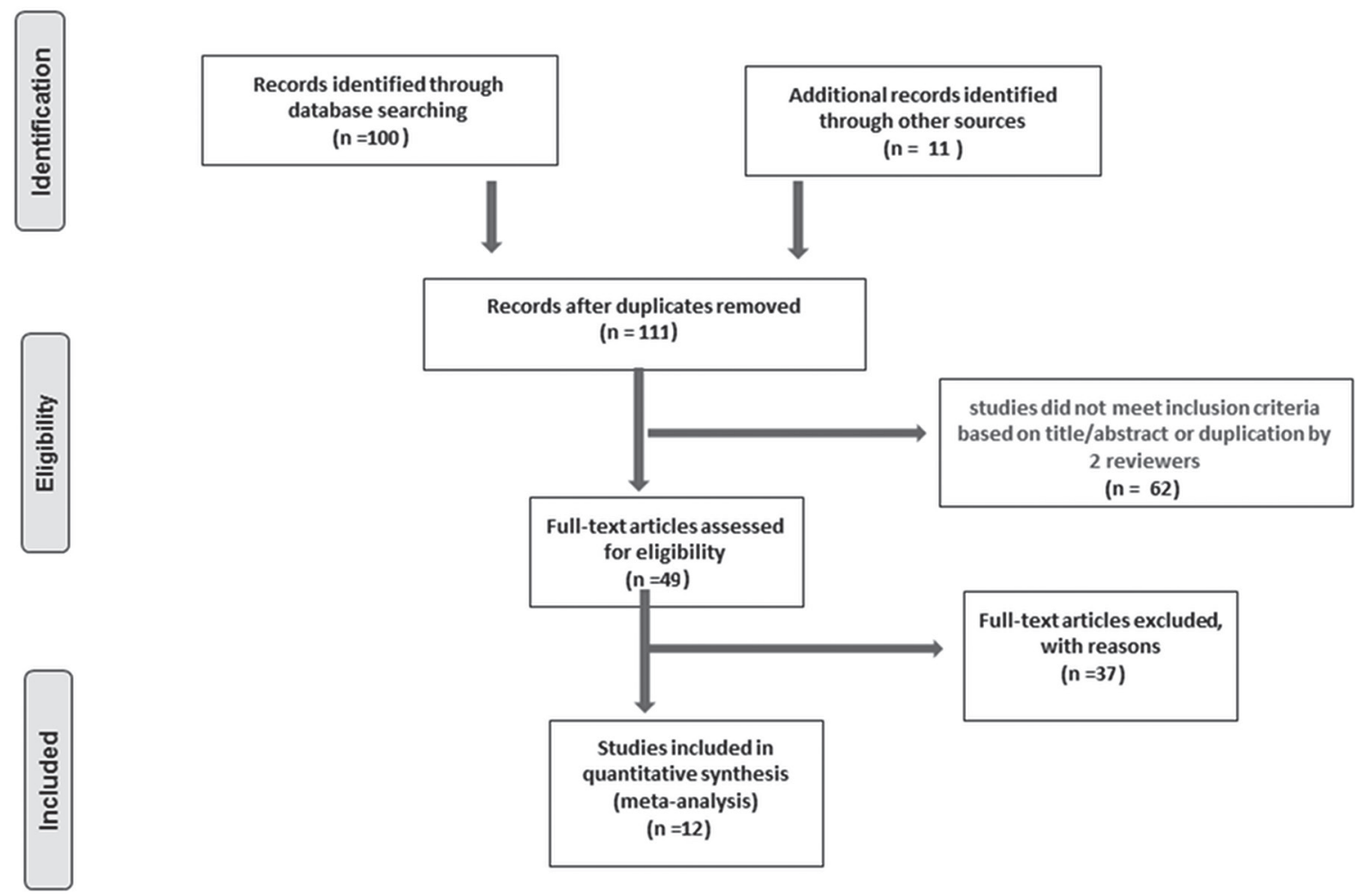

Full-text articles excluded,

with reasons

( $\mathbf{n = 3 7})$

Figure 1 - Flow diagram of the study selection process (based on PRISMA 2009). 
TABLE I

Characteristics of primary diagnostic studies on ovarian cancer diagnosis; all patients had mesothelin level (index test) and histology (reference standard).

\begin{tabular}{|c|c|c|c|c|c|c|}
\hline \multirow[t]{2}{*}{ First author } & \multirow[t]{2}{*}{ Country } & \multirow{2}{*}{$\begin{array}{l}\text { Design and Settings } \\
\text { (all cross-sectional) }\end{array}$} & \multirow[t]{2}{*}{$\mathbf{N}$} & \multicolumn{2}{|c|}{$\begin{array}{c}\text { Population description } \\
\text { Age (Median/range) }\end{array}$} & \multirow[t]{2}{*}{$\begin{array}{r}\text { Cut-off } \\
\text { (nmol/l) }\end{array}$} \\
\hline & & & & Benign & Malign & \\
\hline Abdel-Azeez et al. 2010 & Egypt & Prospective & 65 & $49.3(31-69)$ & $55.3(33-72)$ & 1.4 \\
\hline Bandiera et al. 2013 & Italy & Prospective & 120 & $58.0(19-84)$ & $62.0(34-86)$ & 1.4 \\
\hline Hassan et al. 2006 & USA & Prospective & 97 & & $61.0(35-79)$ & - \\
\hline Ho et al. 2005 & USA & Prospective & 68 & & $63.0(37-80)$ & - \\
\hline Ibrahim et al. 2014 & Egypt & Prospective & 96 & $38.9(22-75)$ & $47.8(20-69)$ & 1.4 \\
\hline McIntosh et al. 2004 & USA & Prospective & 95 & - & - & - \\
\hline Moraes 2012 & Brazil & Prospective & 138 & - & - & 1.5 \\
\hline Qiao and Li 2012 & China & Prospective & 90 & $51.9(44-60)$ & $56.7(46-62)$ & 2.5 \\
\hline Scholler et al. 1999 & USA & Retrospective & 27 & - & $61.0(35-79)$ & - \\
\hline Scholler et al. 2008 & USA & Retrospective & 336 & $57.0^{\mathrm{b}}(19-87)$ & $57.0(19-87)$ & - \\
\hline Shah et al. 2009 & USA & Retrospective & 267 & $54.0(25-83)$ & $58.0(19-86)$ & - \\
\hline Wu et al. 2014 & China & Prospective & 162 & $48(36-70)$ & $55(39-80)$ & 1.3 \\
\hline Total & & & 1561 & & & \\
\hline
\end{tabular}

${ }^{\mathrm{b}}$ Median age of all patients.

as having a high risk of bias. The results of the quality assessment were presented in Figure 2 for the 12 included studies.

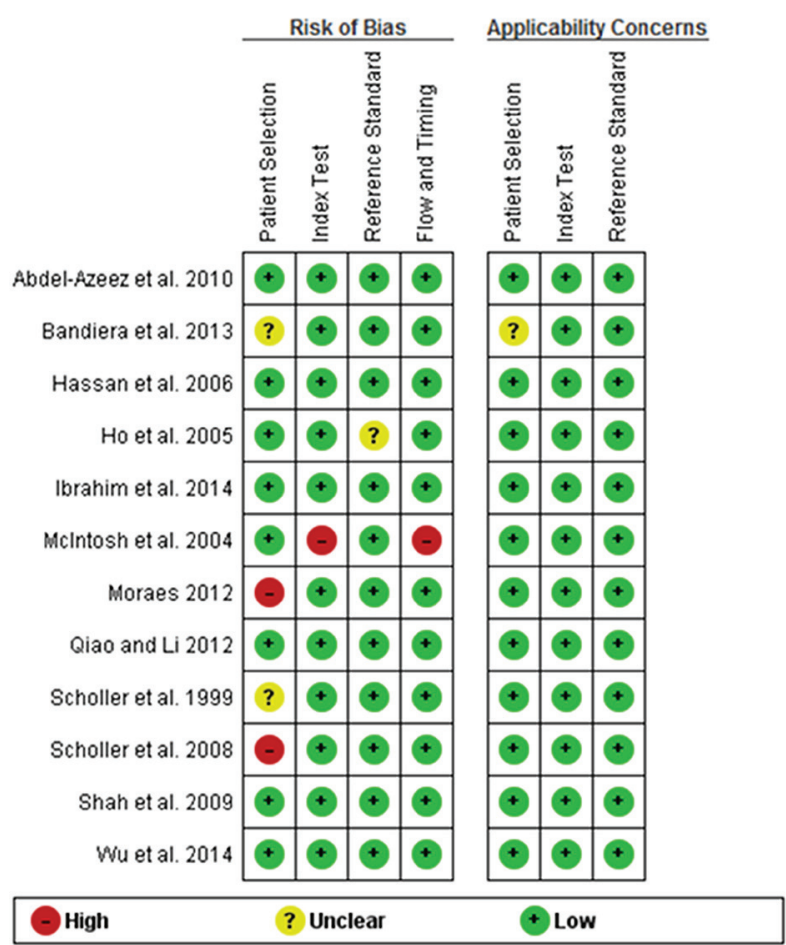

Figure 2 - Results of the evaluation of each study according to QUADAS-2. See the colors in the online version.
The robustness of the results was tested by repeating the analysis using a different statistical model (random effects model). Pooling sensitivity, specificity, and the DOR from the three studies with high risk of bias did not alter the accuracy rate of the analysis with all twelve studies. The area under the curve (SROC) and the statistic $\mathrm{Q}^{*}$ also preserved its magnitude. Therefore, all 12 studies selected were included in the meta-analysis.

Mesothelin had a pooled sensitivity of 0.62 (CI 95\% 0.58-0.66) for the detection of malignant ovarian tumors. The estimates for heterogeneity were highly consistent across studies: for normal or benign lesions vs. malignant lesions $(\mathrm{QT}=182$, $\mathrm{p}=0.0001$; inconsistency $I^{2}=94 \%$ ).

In general, specificity was higher for normal or benign lesions vs. malignant ovarian tumors, with a pooled specificity of 0.94 (CI 95\% 0.92-0.95). The estimates for heterogeneity were highly consistent across studies: QT $=52.4 \mathrm{p}=0.0001$, inconsistency $I^{2}=79 \%$ (Figure 3 ).

The Diagnostic odds ratio (DOR) between malignant ovarian cancer and benign lesions 


$\begin{array}{lrrrrc}\text { Study } & \text { TP } & \text { FP } & \text { FN } & \text { TN } & \text { Sensitivity }(95 \% \text { CI) } \\ \text { Abdel-Afzeez et al. 2010 } & 35 & 11 & 6 & 13 & 0.85[0.71,0.94] \\ \text { Bandiera et al. 2013 } & 57 & 2 & 3 & 58 & 0.95[0.86,0.99] \\ \text { Hassan et al. 2006 } & 14 & 5 & 7 & 71 & 0.67[0.43,0.85] \\ \text { Ho et al. 2005 } & 10 & 0 & 14 & 44 & 0.42[0.22,0.63] \\ \text { Ibrahim et al. 2014 } & 37 & 1 & 1 & 57 & 0.97[0.86,1.00] \\ \text { Mclntosh et al. 2004 } & 22 & 1 & 30 & 42 & 0.42[0.29,0.57] \\ \text { Moraes 2012 } & 14 & 10 & 7 & 107 & 0.67[0.43,0.85] \\ \text { Qiao and Li 2012 } & 34 & 8 & 8 & 40 & 0.81[0.66,0.91] \\ \text { Scholler et al. 1999 } & 20 & 0 & 1 & 6 & 0.95[0.76,1.00] \\ \text { Scholler et al. 2008 } & 44 & 11 & 72 & 209 & 0.38[0.29,0.47] \\ \text { Shah et al. 2009 } & 55 & 6 & 88 & 118 & 0.38[0.30,0.47] \\ \text { Wu et al. 2014 } & 64 & 2 & 14 & 82 & 0.82[0.72,0.90]\end{array}$

Pooled Sensitivity $=0.62$ (0.58 to 0.66$)$

Chi-square $=182.86 ; \mathrm{df}=11(\mathrm{p}=0.0000)$

Inconsistency (I-square) $=94.0 \%$

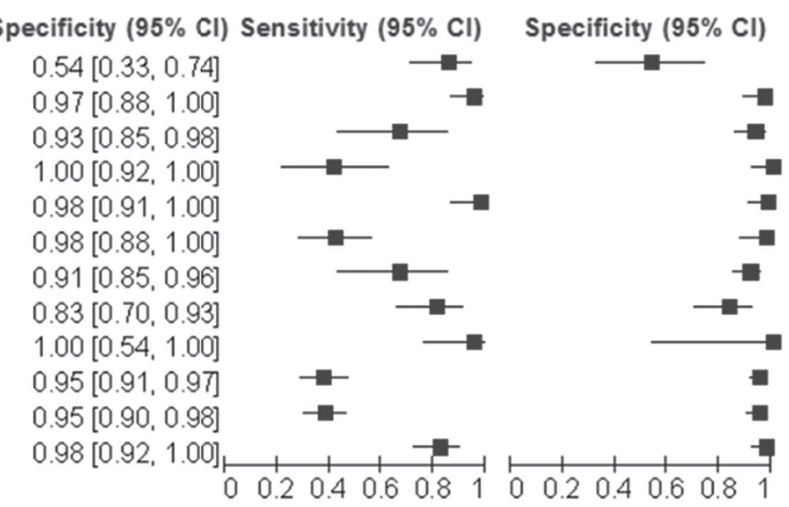

Pooled Sensitivity $=0.94$ (0.92 to 0.95 )

Chi-square $=52.42 ; \mathrm{df}=11(\mathrm{p}=0.0000)$

Inconsistency (I-square) $=79.0 \%$

Figure 3 - Florest plot showing of sensitivity and specificity pool.

was $38.92(95 \%$ CI 17.82-84.99; $\mathrm{QT}=41.2, \mathrm{p}=$ 0.0001 ; inconsistency $I^{2}=73.3 \%$ ). SROC curves were constructed due to heterogeneity in the DOR. For malignant ovarian tumors vs. benign lesions the AUC was 0.94 and $\mathrm{Q}^{*}=0.88$ with standard errors 0.03 and 0.04 , respectively (Figure 4).

Begg's funnel plot and Egger's test was performed to assess the publication bias of the literature in all comparison models. The shape of the funnel plot revealed evidence of obvious asymmetry. The Egger's regression method and Begg's bias test were used to provide statistical evidence of funnel plot symmetry ( $\mathrm{p}$ for bias= 0.006) (Figure 5).

We performed a meta-regression analysis to investigate heterogeneity. The meta-regression analysis indicated no association between the mean age, cut-off, type of study with outcome (Table II).

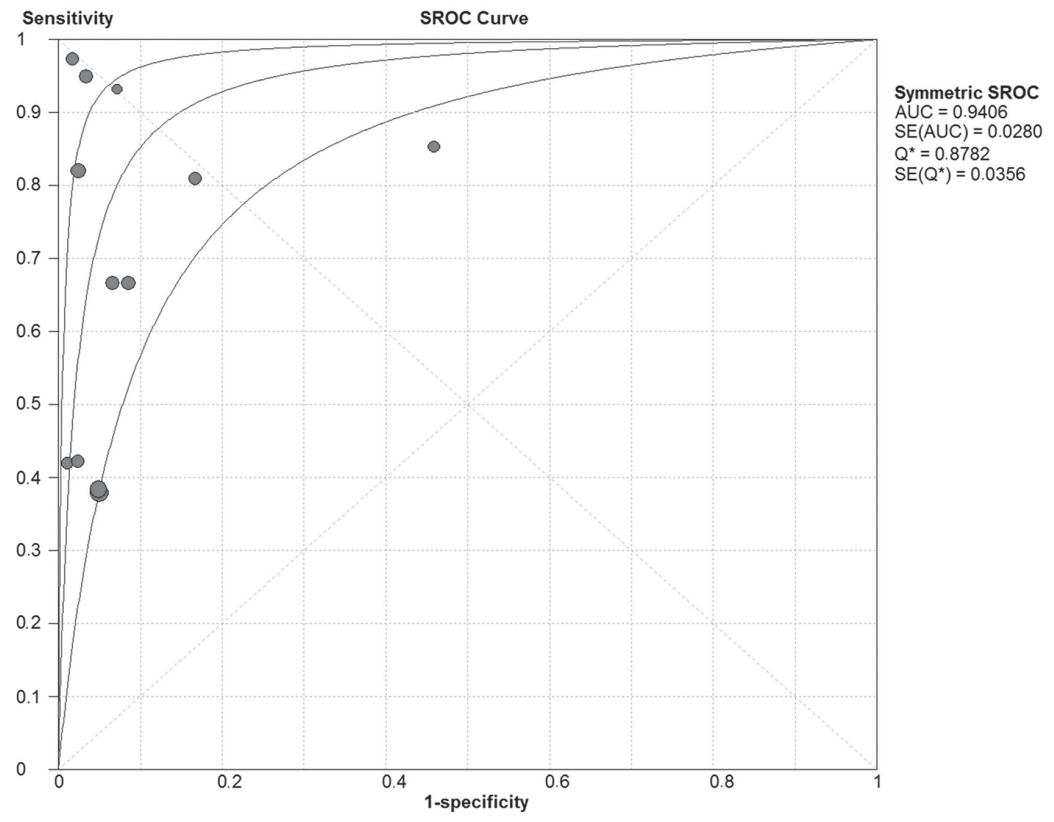

Figure 4 - Summary receiver operating characteristic curves (SROC). 


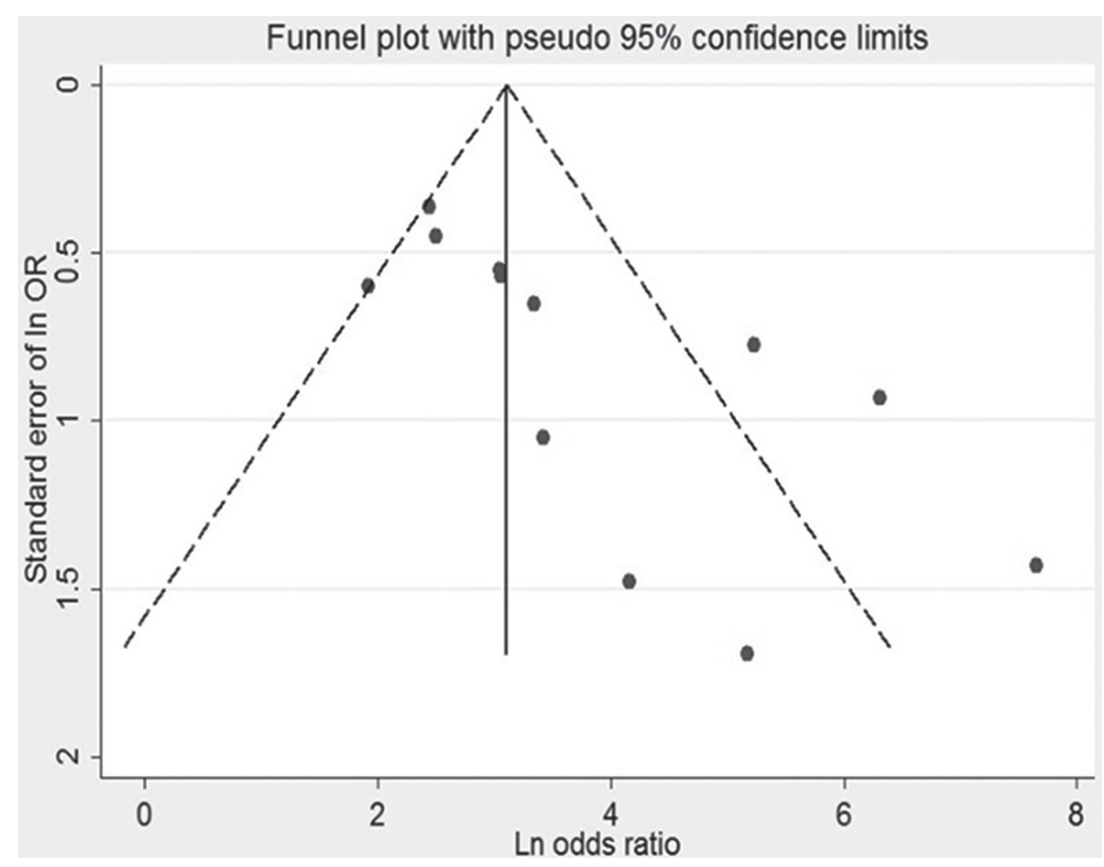

Figure 5 - Funnel plot of estimated publication bias.

TABLE II

Meta-regression results.

\begin{tabular}{clccc}
\hline Variable & Model & Coef $(\mathbf{B})$ & $\mathbf{9 5 \%} \mathbf{C I}$ & \multicolumn{1}{c}{ P } \\
\hline Cut-off & Continuous & 1.27 & $-3.87-6.41$ & 0.530 \\
Study type & Categorical & -1.51 & $-4.33-1.29$ & 0.249 \\
Age & Continuous & -1.20 & $-5.27-2.86$ & 0.49 \\
\hline
\end{tabular}

Each variable was analysed separately in a meta regression model (lnOR). Coef(B) represents the regression coefficient of each linear regression representing the slope of each model. 95\% IC is the confidence interval of the beta coefficient values.

\section{DISCUSSION}

Our study showed a high specificity and low sensitivity for mesothelin in the diagnosis of ovarian cancer.

There has been immense effort over the last few years to identify more promising biomarkers. The mesothelin screening test could be an important screening test for ovarian cancer. It may be possible to improve the sensitivity of this test in combination with another biomarker, especially in the early stages of disease, because when mesothelin is negative, there is a high probability of nonmalignancy.
Previously, a panel of biomarkers was examined, and it was found that the dual marker combination of HE4 and CA 125 produced the highest sensitivity of the various tumor marker combinations and increased the sensitivity of CA 125 alone (Moore et al. 2008) An algorithm utilizing HE4 and CA 125 successfully classified patients into highand low-risk groups (Moore et al. 2009).

On the other hand, in our study, although the pool of test sensitivity was relatively low, the chance of finding cancer in women with increased levels of mesothelin was 38.92 times as high as in women with normal levels. 
Human mesothelin is produced as a $69 \mathrm{kDa}$ polypeptide with a hydrophobic sequence at the carboxyl end that is removed and replaced by phosphatidylinositol. This glycosyl-phosphatidylinositol linkage anchors mesothelin to the cell membrane (Chang and Pastan 1996, Hassan et al. 2006) MSLN is hypothesized to be involved in cell adhesion and signaling (Chang and Pastan 1996) and to contribute to the metastasis of ovarian cancer to the peritoneum by binding CA 125 (Rump 2004, Gubbels et al. 2006). CA 125 is the most widely used serum biomarker among patients with ovarian cancer. Its utility as a marker for the detection of recurrent disease is well established. A metaanalysis, which included 2374 women, revealed that for CA 125 levels, the pooled sensitivity for the diagnosis of borderline tumors or ovarian cancer was 0.80 (CI 95\% 0.76-0.82) and the specificity was 0.75 (CI 95\% 0.73-0.77) (Medeiros et al. 2009).

The biological functions of mesothelin remain largely unknown, as mesothelin knockout mice do not show a detectable phenotype (Bera and Pastan 2000). It has been suggested that mesothelin plays a role in tumor adhesion and metastasis based on evidence that it can bind to MUC16 (also known as CA 125), which is highly glycosylated, to mediate heterotypic cell adhesion (Imashimizu et al. 2011).

It has been reported that blood mesothelin levels are useful for the early detection of mesothelioma and postoperative monitoring for its recurrence (Huang et al. 2006). Moreover, 12\% of patients had elevated serum mesothelin levels, suggesting the potential of mesothelin as an early detection biomarker. A study found that mesothelin and CA 125 as combined biomarkers provided greater sensitivity for the early diagnosis of ovarian cancer (McIntosh et al. 2004).

Recent meta-analisys found that the diagnostic accuracy of HE4 in ovarian cancer is better than that of soluble mesothelin-related protein: HE4 sensitivity 0.74 (CI 95\% 0.72-0.77) and mesothelin 0.49 (CI 95\% 0.45-0.53) respectively and specificity HE4 $=0.86$ (CI 95\% 0.84-0.87) and Mesothelin 0.95 (CI 95\% 0.93-0.96) respectively. Combinations of the two markers show more sensitivity and specificity 0.78 (CI 95\% 0.70-0.84) and 0.94 (CI 95\% 0.90-0.97) respectively (Lin et al. 2012).

Our study demonstrated a pooled sensitivity of $62 \%$ and specificity of $0.94 \%$. The concept of specificity is the proportion negative test results among the "healthy", which formula is TN/(TN + FP). This means that this test have negative results in $94 \%$ of patients without disease (ovarian cancer) and positive results in $10 \%$ of patients without disease (false-positive). A test with high specificity is useful for confirming a diagnosis because have few results that are falsely positive.

It is important to note that a possible limitation of this systematic review was the high heterogeneity found between studies because it is from observational studies with populations, study designs and different cut-off points. Heterogeneity is to be expected in meta-analyses of diagnostic test accuracy. In test accuracy reviews large differences are commonly noted between studies, indicating that actual test accuracy varies between the included studies, or that there is heterogeneity in test accuracy. Univariate tests for heterogeneity in sensitivity and specificity and the estimates of the $I^{2}$ statistic are not routinely used in Cochrane DTA reviews, as they do not account for heterogeneity explained by phenomena such as positivity threshold effect (Whiting et al. 2011).

However, this meta-analysis was conducted with the criteria for performing a rigorous systematic review planned a priori according to a prospective protocol and using PRISMA statement guidelines (Rosa et al. 2014, Whiting et al. 2011). We adhered to the most recent guidelines for conducting diagnostic reviews, as describe in the Cochrane Diagnostic Reviewers' Handbook (Reitsma et al. 2005). We used an extensive search strategy without a methodological filter and not use 
any language restriction. There were quite a few discrepancies in the phase of abstract selection and the agreement on some items of QUADAS-2.

In conclusion, our systematic review shows that although mesothelin cannot serve alone as a marker for the detection of ovarian cancer, it might be used in combination with CA 125 and/or HE4 to achieve greater sensitivity.

\section{ACKNOWLEDGMENTS}

We would like to thanks University of Extremo Sul Catarinense for the financial support.

\section{RESUMO}

O objetivo deste trabalho foi avaliar a acurácia da mesotelina como um biomarcador para o câncer de ovário. Realizou-se uma revisão sistemática quantitativa. Uma pesquisa global nas bases de dados Medline, LILACS, SCOPUS, Embase, Cochrane Central Register of Controlled Trials, Biomed Central, e ISI Web of Science foi realizada de janeiro de 1990 a junho de 2015. Para a inclusão nesta revisão sistemática, os estudos deveriam ter mensurado os níveis mesotelina em pelo menos dois diagnósticos histológicos; câncer de ovário (câncer de ovário ou limítrofe) vs. tumores de ovário benignos ou normais. Para cada estudo foram construídas tabelas de contingência $2 \times 2$. Calculou-se a sensibilidade, especificidade e odds ratio diagnóstica globais. A qualidade dos estudos foi realizado de acordo com o QUADAS-2. A análise estatística foi realizada com o software Stata 11, Meta-DiSc $\AA$ e RevMan 5.2. Doze estudos foram realizados incluindo 1.561 mulheres. A sensibilidade agrupada foi de 0,62 (IC 95\% 0,580,66 ) e a especificidade foi de 0,94 (IC 95\% 0,92-0,95). A DOR foi 38,92 (IC 95\% 17,82-84,99). Nossa revisão sistemática mostrou que a mesotelina não pode servir como um biomarcador isolado para o câncer de ovário.

Palavras-chave: tumores de ovário, mesothelin, metaanálise, biomarcador, estatística.

\section{REFERENCES}

ABDEL-AZEEZ HA, LABIB HA, SHARAF SM AND REFAI AN. 2010. HE4 and mesothelin: novel biomarkers of ovarian carcinoma in patients with pelvic masses. Asian Pac J Cancer Prev 11: 111-116.

ALTMAN DG. 1999. Some common problems in medical research. In: Altman DG (Ed), Practical statistics for medical research, $9^{\text {th }}$ ed., London: Chapman: 396-439.

BANDIERA E ET AL. 2013. Cancer antigen 125, human epididymis 4, kallikrein 6, osteopontin and soluble mesothelinrelated peptide immunocomplexed with immunoglobulin $\mathrm{M}$ in epithelial ovarian cancer diagnosis. Clin Chem Lab Med 51: 1815-1824.

BERA TK AND PASTAN I. 2000. Mesothelin is not required for normal mouse development or reproduction. Mol Cell Biol 20: 2902-2906

CHANG K AND PASTAN I. 1996. Molecular cloning of mesothelin, adifferentiation antigen present on mesothelium, mesotheliomas, and ovarian cancers. Proc Natl Acad Sci 93: 136-140.

DEEKS JJ, MACASKILL P AND IRWIG L. 2005. The performance of tests of publication bias and other sample size effects in systematic reviews of diagnostic test accuracy was assessed. J Clin Epidemiol 58: 882-893.

GATSONIS C AND PALIWAL P. 2006. Meta-analysis of diagnostic and screening test accuracy evaluations: methodologic primer. Am J Roentgenol 187: 271-281.

GUBBELS JA ET AL. 2006. Mesothelin-MUC16 binding is a high affinity, $\mathrm{N}$-glycan dependent interaction that facilitates peritoneal metastasis of ovarian tumors. Mol Cancer 5: 50.

HASSAN R, REMALEY AT, SAMPSON ML, ZHANG J, COX DD, PINGPANK J, ALEXANDER R, WILLINGHAM M, PASTAN I AND ONDA M. 2006. Detection and quantitation of serum mesothelin, a tumor marker for patientswith mesothelioma and ovarian cancer. Clin Cancer Res 12: 447-453.

HO M, HASSAN R, ZHANG J, WANG QC, ONDA M, BERA T AND PASTAN I. 2005. Humoral immune response to mesothelin in mesothelioma and ovarian cancer patients. Clin Cancer Res 11: 3814-3820.

HUANG CY, CHENG WF, LEE CN, SU YN, CHIEN SC, TZENG YL, HSIEH CY AND CHEN CA. 2006. Serum mesothelinin epithelial ovarian carcinoma: a new screening marker and prognostic factor. Anticancer Res 26: 4721-4728.

IBRAHIM M, BAHAA A, IBRAHIM A, EL HAKEM AA, ABO-EL NOOR A AND EL TOHAMY U. 2014. Evaluation of serum mesothelin in malignant and benign ovarian masses. Arch Gynecol Obstet 290: 107-113.

IMASHIMIZU K, SHIOMI K, MAEDA M, AOKI N, IGARASHI K, SuzUKi F, KoIzumi M, SUZUKi K AND Hino O. 2011. Feasibility of large-scale screening using N-ERC/ mesothelin levels in the blood for the early diagnosis of malignant mesothelioma. Exp Ther Med 2: 409-411.

IRWIG L, TOSTESON AN, GATSONIS C, LAU J, COLDITZ G, CHALMERS TC AND MOSTELLER F. 1994. Guidelines for meta-analyses evaluating diagnostic tests. Ann Intern Med 120: $667-676$. 
Jemal A, Siegel R, Ward E, Murray T, Xu J, Smigal C AND THUn MJ. 2009. Cancer statistics. CA Cancer J Clin 59: 225-249.

KOBEL M ET AL. 2008. Ovarian carcinoma subtypes are different diseases: implications for biomarker studies. PLOS Med 5: 232.

Liberati A, Altman DG, Tetzlaff J, Mulrow C, GOTZSCHE PC, IOANNIDIS JPA, CLARKE M, DEVEREAUX PJ, KLEIJNEN J AND MOHER D. 2009. The PRISMA statement for reporting systematic reviews and metaanalysis of studies that evaluate healthcare interventions: explanation and elaboration. BMJ 339: b2700.

LIN JY, QIN JB, LI XY, DONG P AND YIN BD. 2013. .Diagnostic value of human epididymis protein 4 compared with mesothelin for ovarian cancer: a systematic review and meta-analysis. Asian Pac J Cancer Prev 13: 5427-5432.

MCINTOSH MW, DRESCHER C, KARLAN B, SCHOLLER N, Urban N, Hellstrom KE AND Hellstrom I. 2004. Combining CA 125 and SMR serum markers for diagnosis and early detection of ovarian carcinoma. Gynecol Oncol 95: 9-15.

MedeIRos LR, Rosa DD, DA Rosa MI AND BozZETTI MC. 2009. Accuracy of CA 125 in the diagnosis of ovarian tumors: a quantitative systematic review. Eur J Obstet Gynecol Reprod Biol 142: 99-105.

MOORE RG. 2008. The use of multiple novel tumor biomarkers for the detection of ovarian carcinoma in patients with a pelvic mass. Gynecol Oncol 108: 402-408.

MoOre RG, MCMEEKIN DS, BROWN AK, DISILVESTRO P, Miller MC, Allard WJ, GaJeWSKi W, KuRMaN R, BAST TCJ AND SKATES SJ. 2009. A novel multiple marker bioassay utilizing HE4 and CA 125 for the prediction of ovarian cancer in patients with a pelvic mass. Gynecol Oncol 112: 40-46.

MORAES DRPL. 2012. Concentration of serum markers and presence of specific symptoms in women with or without adnexal masses. Universidade Estadual de Campinas, São Paulo.

QIAO N AND LI H. 2013. The value of mesothelin in the diagnosis and follow-up of surgically treated ovarian cancer. Eur J Gynaecol Oncol 34: 163-165.
REITSMA JB, GLAS AS, RUTIES AW, SCHOLTEN RJ, BOSSUYT PM AND ZWINDERMAN AH. 2005. Bivariate analysis of sensitivity and specificity produce informative summary measures in diagnostic reviews. J Clin Epidemiol 58: $982-$ 990.

ReView Manager (REVMan) [COMPUter Program]. 2012.Version 5.2. Copenhagen: The Nordic Cochrane Centre, The Cochrane Collaboration.

RUMP A, MORIKAWA Y, TANAKA M, MINAMI S, UMESAKI N, TAKEUCHI M AND MIYAJIMA A. 2004. Binding of ovarian cancer antigen CA 125/MUC 16 to mesothelin mediates cell adhesion. J Biol Chem 279: 9190-9198.

SCHOLler N, FU N, YANG Y, YE Z, GOODMAN GE, HELlSTRÖM KE AND HELlSTRÖM I. 1999. Soluble member(s) of the mesothelin/megakaryocyte potentiating factor family are detectable in sera from patients with ovarian carcinoma. Proc Natl Acad Sci 96: 11531-11536.

SCHOLLER N ET AL. 2008. Use of yeast-secreted in vivo biotinylated recombinant antibodies (Biobodies) in beadbased ELISA. Clin Cancer Res 14: 2647-2655.

SHAH CA ET AL. 2009. Influence of ovarian cancer risk status on the diagnostic performance of the serum biomarkers mesothelin, HE4, and CA125. Cancer Epidemiol Biomarkers Prev 18: 1365-1372.

Siege LR, Naishadham D AND Jemal A. 2013. Cancer statistics. CA Cancer J Clin 63: 11-30.

STATACORP. 2013. Stata Statistical Software. College Station, TX: StataCorp LP.

Whiting PF, Rutjes AW, Westwood ME, Mallett S, DEEKS JJ, REITSMA JB, LEEFLANG MM, STERNE JA AND BOSSUYT PM. 2011. QUADAS-2 Group. QUADAS-2: a revised tool for the quality assessment of diagnostic accuracy studies. Ann Intern Med 155: 529-536.

WU X, LI D, LIU L, LIU B, LIANG H AND YANG B. 2014. Serum soluble mesothelin-related peptide (SMRP): a potential diagnostic and monitoring marker for epithelial ovarian cancer. Arch Gynecol Obstet 289: 1309-1314.

ZAMORA JAV, MURIEL A, KHAN KS AND COOMARASAMY A. 2006. Meta-DiSc: a software for meta-analysis of test accuracy data. BMC Medical Research Methodology 6: 31. 